\title{
Workshop Menu MP-ASI untuk Menjaga Status Gizi Balita di Kota Mataram
}

\author{
Baiq Fitria Rahmiati ${ }^{1}$, Nurul Hidayah ${ }^{2}$, Junendri Ardian $^{3}$, M. Thontowi Jauhari ${ }^{4}$, Febriana \\ Wenny Wijaya ${ }^{5}$ \\ baiqfitria@universitasbumigora.ac.id ${ }^{1}$, nurulhidayah@universitasbumigora.ac.id ${ }^{2}$, \\ ardianjunendri@universitasbumigora.ac.id ${ }^{3}$, thontowi@universitasbumigora.ac.id ${ }^{4}$, \\ wennyfebriana19@gmail.com ${ }^{5}$ \\ 1,2,3,4,5 Universitas Bumigora
}

Article History:

Received: 23-12-2020

Accepted: 28-01-2021

Keywords: Counseling, Infant, Complementary Food.

\begin{abstract}
Basic Health Research Data 2018 states that the prevalence of malnutrition in infants is $18.8 \%$. MPASI, complementary food to breast milk, is food or drink containing nutrients, given to babies or infants aged 6-24 months, and given in stages according to the age and digestive capacity of the babies or infants to meet their nutritional needs other than breast milk. This dedication aims to improve the nutritional status of infants under five years old by providing nutrition education to mothers of children under five related to the provision of complementary feeding recommended by WHO. The method used is counseling to 30 mothers of toddlers in Mataram City. The results of the community service activity show that there is an increase related to participants' knowledge of complementary foods, solving problems for children who do not want to eat and an increase in commitment to make complementary foods according to those recommended by WHO. The conclusion of this dedication is an increase in knowledge and willingness of mothers to provide food in accordance with WHO recommendations.
\end{abstract}

\section{Pendahuluan}

1000 Hari Pertama Kehidupan (1000 HPK) adalah masa emas tumbuh kembang seorang anak. 1000 HPK dihitung mulai dalam masa kandungan hingga anak usia 2 tahun. Dalam periode emas ini, pertumbuhan dan perkembangan berjalan sangat pesat dan begitu menentukan karena tumbuh kembang dimasa datang ditentukan berdasarkan status gizi pada masa 1000 HPK.

Saat ini, Indonesia masih memiliki permasalahan gizi yang cukup serius. Masalah gangguan tumbuh kembang pada bayi usia di bawah dua tahun merupakan masalah yang perlu ditanggulangi dengan serius. Hal ini disebabkan usia bayi di bawah dua tahun merupakan masa yang amat penting sekaligus masa kritis dalam proses tumbuh kembang anak baik secara fisik maupun kecerdasan. Selain itu, usia 6 bulan sampai dengan 24 bulan merupakan masa rawan pertumbuhan bagi bayi dan anak. Data Riset Kesehatan Dasar 
tahun 2013 menyebutkan bahwa Indonesia memliki prevalensi balita dengan status gizi kurus sebesar 12,1\% dan balita dengan status gizi stunting sebesar 37,2\%. Hasil survey Pemantauan Status Gizi (PSG) tahun 2016 menunjukkan bahwa prevalensi stunting pada balita sebesar $27,5 \%$, balita kurus $8,0 \%$,balita sangat kurus $3,1 \%$, dan balita risiko kurus $22,8 \%$.

Permasalahan gizi yang terjadi, tidak lepas dari faktor asupan makan balita. Pemberian makanan untuk balita berusia diatas 6 bulan dinamakan Makanan Pendamping Air Susu lbu atau MPASI. Untuk mengatasi permasalahan gizi yang terjadi, maka direkomendasikan pemberian makanan pendamping air susu ibu (MPASI) pada saat yang tepat dengan tujuan untuk pemenuhan kebutuhan gizi dan tumbuh kembang anak. Kurang gizi pada bayi bukan merupakan faktor utama yang disebabkan oleh kekurangan makanan. Faktor lain yang menjadi penyebab ialah pemberian MPASI yang tidak adekuat dan penyapihan yang terlalu cepat (Darmawan \& Sinta, 2015).

MPASI adalah makanan dan minuman pendamping ASI yang mengandung zat gizi, diberikan kepada bayi berusia 6-24 bulan. MPASI diberikan secara bertahap sesuai dengan kebutuhan gizi bayi dan kesiapan pencernaan. MPASI dibutuhkan karena pada usia 6-24 bulan, ASI hanya menyediakan 1/2 kebutuhan gizi bayi, dan pada usia 12-24 bulan, ASI menyediakan 1/3 dari kebutuhan gizinya (Kemenkes, 2014). Selain itu, pada usia ini perkembangan bayi juga sudah cukup siap untuk menerima makanan lain (Pérez Lizaur, 2011) sehingga MPASI harus diberikan pada saat bayi berusia enam bulan. Menurut Peraturan Pemerintah Nomor 33 Tahun 2012, MPASI yang tepat sejak usia enam bulan dan meneruskan pemberian ASI sampai usia dua tahun merupakan pola pemberian makan terbaik untuk bayi sejak lahir sampai anak berusia dua tahun. Penerapan pola pemberian makan ini akan memengaruhi derajat kesehatan dan meningkatkan status gizi bayi. Agar pemberian MPASI terlaksana dengan baik, diperlukan pengetahuan yang baik pula mengenai MPASI. Beberapa penelitian menunjukan bahwa pengetahuan yang baik dapat menjadikan perilaku terhadap sesuatu menjadi baik pula. Hal ini didukung oleh penelitian Notoatmodjo 2010 yang menyatakan bahwa ibu dengan pengetahuan tentang MPASI baik akan menghasilkan perilaku terhadap pemberian MPASI juga baik (Notoatmodjo, 2010).

Salah satu upaya preventif yang dapat dilakukan dalam mencegah gizi kurang adalah melakukan edukasi pada ibu tentang pentingnya zat gizi bagi pertumbuhan anak. Penyuluhan kesehatan masyarakat adalah upaya memberdayakan individu, kelompok, dan masyarakat untuk memelihara, meningkatkan, dan melindungi kesehatan melalui peningkatan pengetahuan, kesadaran, dan kemampuan, serta mengembangkan iklim yang mendukung, yang dilakukan dari, oleh, dan untuk masyarakat, sesuai dengan sosial budaya dan kondisi setempat (Lailiyana, Nurmailis, 2010). Jenis metode penyuluhan kesehatan sangat beragam. Salah satunya adalah metode ceramah, yakni penyuluh lebih dominan 
memberikan materi, sedangkan peserta lebih dominan mendengarkan (Presska A.K, Cicilia, T.S., Rahayu, 2012). Berdasarkan uraian tersebut, tujuan kegiatan pengabdian kepada masyarakat ini adalah meningkatkan pengetahuan ibu anak usia 6-24 bulan tentang MPASI melalui metode penyuluhan yang dilakukan di jalan Pendidikan no.9, Mataram.

\section{Metode}

Kegiatan pengabdian kepada masyarakat dilaksanakan pada Maret 2020 di salah satu Cafe di Mataram. Kegiatan dilakukan dalam satu kali penyuluhan. Penyuluhan dihadiri tiga puluh responden yang mengikuti kegiatan penyuluhan. Kegiatan ini mengobservasi perubahan sebelum dan sesudah perlakuan. Terdapat soal pilihan ganda yang harus dijawab oleh responden tentang MPASI. Saat penyuluhan, pemateri menggunakan media bantu seperti leaflet, booklet,poster, papan tulis dan spidol. Materi yang diberikan di antaranya pengertian MPASI, syarat MPASI, dampak pemberian MPASI jika terlalu cepat ataupun terlalu lama, manfaat MPASI, serta prinsip pemberian MPASI berdasarkan usia bayi. Kuesioner yang diberikan terdiri atas pertanyaan mengenai MPASI yang sudah dijelaskan pada saat pemaparan materi. Leaflet yang diberikan juga berisi tentang materi yang sama dengan materi yang dijelaskan pada saat pemaparan. Booklet berisi tentang materi menu-menu MPASI yang baik untuk pemenuhan gizi anak dan bisa diterapkan ibu untuk anak usia 6-24 bulan.

Kegiatan pengabdian kepada masyarakat ini diukur melalui pengisian kuesioner yang dibagi menjadi sebelum intervensi dan setelah intervensi. Tujuannya untuk mengetahui tingkat pengetahuan ibu mengenai MPASI sebelum dan sesudah perlakuan. Sasaran kegiatan ini diprioritaskan untuk ibu dengan anak usia 6-24 bulan. Pada penyuluhan ini, evaluasi dilakukan dengan menggunakan post test yang dibagikan setelah pemaparan materi. Hal tersebut dilakukan untuk mengetahui apakah kegiatan penyuluhan yang dilakukan berhasil meningkatkan pengetahuan responden mengenai pemberian MPASI atau tidak. Pada saat penyuluhan ini dilakukan, sebanyak tiga puluh responden datang bersama balita mereka. Proses pemaparan materi berlangsung cukup baik. Terdapat beberapa responden yang bertanya mengenai pemberian MPASI. Namun, ada juga beberapa responden yang tidak fokus karena anak yang sudah mulai rewel atau tidak bisa diam.

\section{Pembahasan}

Karakteristik responden dalam pengabdian ini antara lain memiliki usia antara 20-45 tahun. Responden merupakan ibu dari anak berusia 6-24 bulan. Sebelum materi diberikan, responden diminta untuk menjawab soal pre test tentang MPASI. Kemudian, setelah materi diberikan, responden diminta kembali untuk mengisi kuesioner post-test. Keberhasilan 
dalam penyampaian materi dapat dilihat dari peningkatan nilai saat post test. Adapun sebaran pengetahuan ibu hamil mengenai MPASI dapat dilihat pada Tabel 1.

Tabel 1. Perubahan Pengetahuan Sebelum dan Setelah Edukasi

\begin{tabular}{lll}
\hline Variabel & Mean & St. Deviasi \\
\hline Pre test & 70 & 12,1 \\
Post test & 85 & 16,2 \\
\hline
\end{tabular}

Sumber : Analisis Data Primer (2020).

Berdasarkan hasil analisis pada Tabel 1 terlihat bahwa nilai rata-rata pengetahuan ibu sebelum dilakukan penyuluhan adalah 70,00 dengan standar deviasi 12,1 . Nilai rataratapengetahuan ibu setelah dilakukan penyuluhan sebesar 85 dengan standar deviasi 16,2. Terdapat perbedaandan peningkatan nilai untuk tingkat pengetahuan ibu setelah penyuluhan. Sebanyak dua puluh orang ibu mengalami peningkatan nilai (skor) dalam menjawab post test dibandingkan dengan pre test, tiga orang ibu tidak mengalami perubahan nilai (skor)antara pre test dan post test, dan sebanyak tujuh orang ibu mengalami penurunan nilai(skor) dalam menjawab post test dibandingkan dengan pre test.

$\mathrm{Hal}$ itu menunjukkan bahwa kegiatan penyuluhan berupa pemberian materi MPASI untuk ibu dengan anak usia 6-24 bulan berjalan dengan baik dan efektif dalam meningkatkan pengetahuan. Setelah mendapatkan materi tentang MPASI, sebagian besar responden menjadi tahu tentang makanan pendamping ASI yang sesuai untuk diberikan kepada anak mereka. Responden juga menjadi tahu bahwa ketika usia 6 bulan, ASI saja sudah tidak cukup memenuhi kebutuhan bayi mereka sehingga perlu ditambahkan makanan pendamping ASI (Rahmiati, 2019).

MPASI diberikan dengan tujuan untuk menambah energi dan zat gizi yang diperlukan bagi bayi, karena setelah 6 bulan ASI saja tidak dapat memenuhi kebutuhan bayi secara terus menerus. Ibu yang memperhatikan pemberian makanan pendamping ASI pada anak berarti bahwa ibu tersebut sangat memperhatikan pertumbuhan anaknya karena dengan memberikan makanan pendamping ASI, ibu telah melengkapi zat gizi sesuai kebutuhan anaknya untuk pertumbuhan dan perkembangan (Datesfordate, Kundre, \& Rottie, 2017).

Penelitian yang dilakukan oleh Nurbaiti, Adi, Devi, \& Harthana (2014) menunjukkan bahwa ada perbedaan rata-rata persentase pengetahuan gizi pada ibu hamil antara sebelum (pre test) dan setelah dilakukan penyuluhan gizi $(p=0,0001)$. Untuk itu, rata rata pengetahuan gizi sebelum diberi penyuluhan gizi sebesar $66,46 \%$ naik menjadi $71,61 \%$. Hal 


\section{ADMA}

Qurnal Pengabdian dan Pemberdayaan Masyarakat

itu juga didukung oleh penelitian Bennu, M., (2012) di posyandu Kabupaten Maros, Sulawesi Selatan.

Gambar 1-3 menunjukan kegiatan yang dilakukan selama penyuluhan berlangsung di jalan Pendidikan no. 9, Mataram

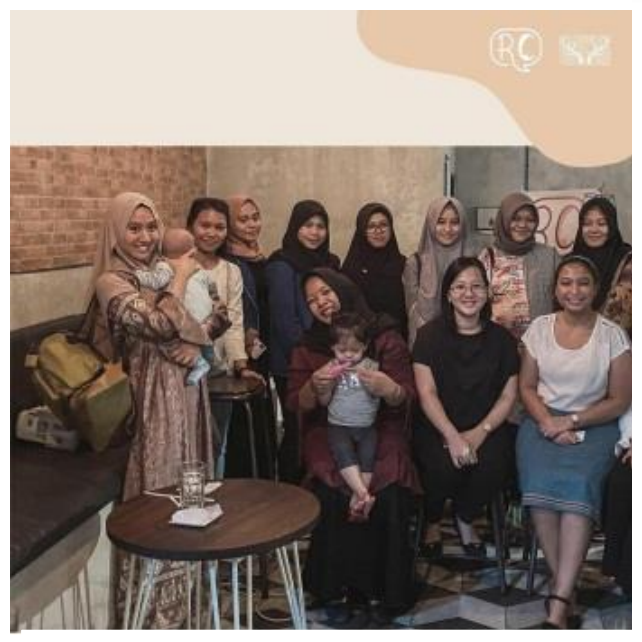

Gambar 1. Sesi foto bersama Pemateri dan Peserta

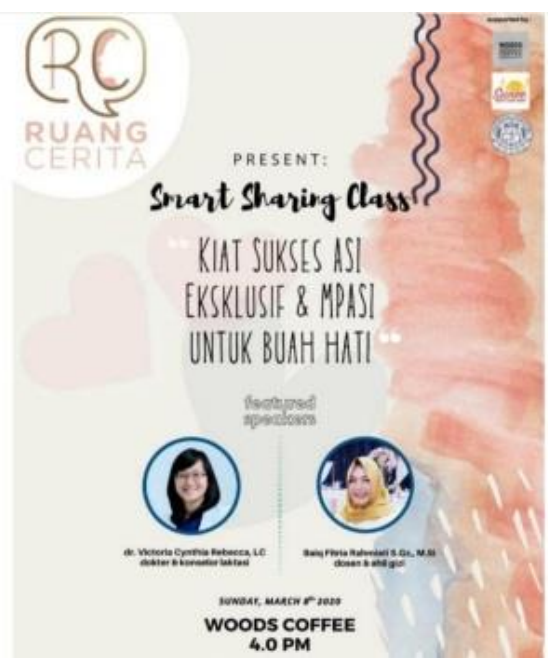

Gambar 2. Undangan

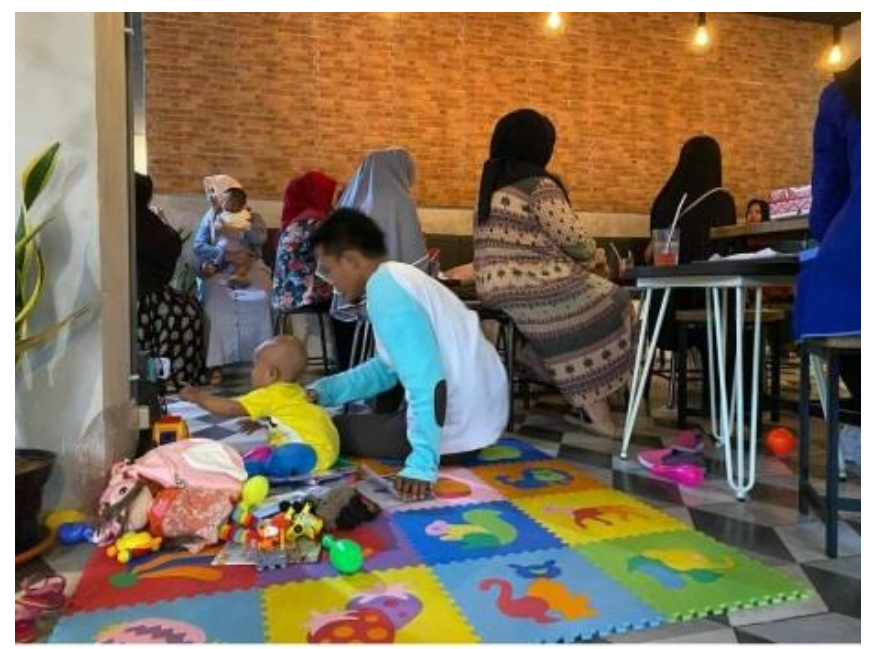

Gambar 3. Ibu balita fokus mendengarkan materi

\section{Kesimpulan}

Nilai rata-rata pada post-test meningkat sebesar 15 poin. Selama pemberian materi berlangsung, ibu balita sangat antusias dibuktikan dengan ketika diberi pertanyaan oleh pemateri, ibu balita bersemangat menjawab pertanyaan dengan benar. Hal tersebut menunjukkan bahwa kegiatan pengabdian berupa edukasi pada ibu dengan bayi usia 6-24 bulan efektif dilakukan dan meningkatkan pengetahauan gizi ibu tentang pemberian MPASI yang tepat demi mencegah terjadinya gizi kurang pada bayi. 


\section{Ucapan Terimakasih}

Terimakasih diucapkan kepada komunitas ruang cerita Lombok yang telah menjadi wadah untuk penyalur informasi kepada sasaran yang membutuhkan. Terimakasih kembali juga diucapkan kepada Universitas Bumigora yang telah memberikan kesempatan untuk berbagi kepada sesama.

\section{Daftar Pustaka}

Baiq Fitria Rahmiati. (2019). Upaya Perbaikan Status Gizi Balita Melalui Sosialisasi Menu Mp-Asi Sesuai Usia Balita Di Kecamatan Gunungsari. JPMB: Jurnal Pemberdayaan Masyarakat Berkarakter, 2(2), 138-145. https://doi.org/10.36765/jpmb.v2i2.8

Bennu, M., D. (2012). No TitleHubungan pemberian makanan pendamping ASI (MP-ASI) dengan status gizi bayi 6-12 bulan di Posyandu Kurusumange, Kecamatan Tanralili Kabupaten Maros. Poltekkes Kesehatan Kemenkes Makassar.

Darmawan, F. H., \& Sinta, E. N. M. (2015). Hubungan pengetahuan dan sikap ibu dengan perilaku pemberian mp-asi yang tepat pada bayi pada usia 6-12 bulan di desa sekarwangi kabupaten sumedang. Midwife Journal, 1(2), 35-36.

Datesfordate, A., Kundre, R., \& Rottie, J. (2017). Hubungan Pemberian Makanan Pendamping Air Susu Ibu (Mp-Asi) Dengan Status Gizi Bayi Pada Usia 6-12 Bulan Di Wilayah Kerja Puskesmas Bahu Manado. Jurnal Keperawatan UNSRAT, 5(2), 137391.

Lailiyana, Nurmailis, S. (2010). Buku ajar kesehatan reproduksi. jakarta: buku kedokteran.EGC.

Notoatmodjo, S. (2010). IImu perilaku kesehatan. jakarta: rineka cipta.

Nurbaiti, L., Adi, A. C., Devi, S. R., \& Harthana, T. (2014). Kebiasaan makan balita stunting pada masyarakat Suku Sasak: Tinjauan 1000 hari pertama kehidupan (HPK). Masyarakat, Kebudayaan Dan Politik, 27(2), 109. https://doi.org/10.20473/mkp.v27i22014.109-117

Pérez Lizaur, A. B. (2011). Complementary Feeding: Report of the Global Consultation, Summary of Guiding Principles. Gaceta Médica de México, 147 Supp/(December), 3945.

Presska A.K, Cicilia, T.S., Rahayu, A. (2012). No TPengaruh penyuluhan kesehatan tentang kecacingan terhadap pengetahuan dan sikap siswa Madrasah Ibtidaiyah An Nur Kelurahan Pedurungan Kidul Kota Semarangitle. Jurnal Promosi Kesehatan Indonesia, 185.

RI, K. (2014). Profil Kesehatan Indonesia 2014. 